\title{
Advent of Artificial Intelligence and its Impact on Top Leading Commercial Banks in India - Case Study
}

\author{
Prof. Lakshminarayana. N1, Ms. Deepthi B. R. ${ }^{2}$ \\ 1Professor, ${ }^{2}$ Student, \\ 1,2SJRCW, Bangalore, Karnataka, India
} \begin{abstract}
(ijtsrd), ISSN: 24566470, Volume-3 | Issue-4, June 2019, pp.614-616, URL: https://www.ijtsrd.c om/papers/ijtsrd23 850.pdf
\end{abstract}

How to cite this paper: Prof. Lakshminarayana. N | Ms. Deepthi B. R. "Advent of Artificial Intelligence and its Impact on Top Leading Commercial Banks in India - Case Study" Published in International Journal of Trend in Scientific Research and Development

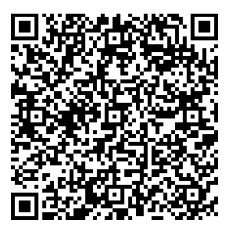
IITSRD23850

Copyright (C) 2019 by author(s) and International Journal of Trend in Scientific Research and Development Journal. This is an Open Access article distributed under the terms of the Creative Commons

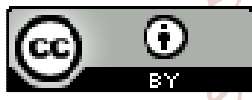
Attribution License (CC BY 4.0) (http://creativecommons.org/licenses/ by/4.0)

to understand the AI to shift from the traditional system which is consuming the time and not providing the customer satisfaction in the banking services. Hence in the growing AI world the need of adoption of AI is the only way to retain clients, improve the process and fulfil the demand of Customer. It can be said that AI could be a Key for transforming the problems of customer and retain the competitive edge.

The term AI was introduced in the year 1950's by John McCarthy, he was the first to define AI as "Science and engineering of making Intelligence machines". Due to the transformation in the Technology, AI is now getting its prominence as there is rapid evolution and significant interest among the Banking Sector to over the competitive pressure. AI is the technology based which results in the performing of various tasks through human Intelligence such as Speech recognition, visual recognition, translation between languages and so on.

The competitive Pressure made the Indian Banking to adopt the AI to overcome the problem throughout the Banking Activities. The Commercial Bank started to use the various Application of AI technology which has resulted in $\$ 5.1$ billion up from $\$ 4.0$ billion through global Investment.
The Indian banking sector is exploring the ways by which it can harness the power of AI to improve the processes and enhance the Customer Service in the long run. The paper seeks to explore the areas where the AI application is being used in the Banking Sector and its implication in the leading banks in India and also to understands the need to cut down cost and the expenditure on redundant tasks.

\section{NEED FOR THE STUDY}

$\mathrm{AI}$ is not new to India. Research institutions and universities have been working with various AI technologies for decades, and especially in the banking sector. With enabling technologies becoming a lot more accessible and inexpensive, $\mathrm{AI}$ is now becoming mainstream, with large enterprises and start-ups looking at different opportunities. Our research study shows that the adoption of AI in banking has the potential to add nearly $\$ 1$ trillion to the Indian economy in 2035. AI adoption is still in its nascent stages, and a lot more needs to be done to realise its full potential.

\section{OBJECTIVES}

1. To identify the opportunities and challenges in Banking Sector with reference to implementation of Artificial Intelligence. 
2. To study about the applications of AI in use in the leading commercial banks in India: State Bank of India, HDFC, ICICI and Axis.

\section{RESEARCH METHODOLOGY}

\section{Type of Research}

The purpose of study will adopt Descriptive Survey and Exploratory Method of Research.

\section{Sampling Technique}

For the purpose of selecting the sample respondents and needed information for the study Judgmental Sampling will be employed.

\section{Sample Size}

To gain the in-depth knowledge on the topic 90 respondents would be selected as sample size.

One nationalized and three private banks are being utilizing the application of AI. Hence, these banks were considered for the study.

\section{FINDINGS}

From the case study of top leading Commercial banks which adopted AI applications in their banking activities have resulted in enamors changes. It is to be found that $\mathrm{AI}$ application is leading the Banking Sector and also helping to fulfill the customer demand faster and easier.

AI applications within banking sector include the following 1. Improving the customer experience

While trying to improve the client experience and set themselves apart, a large portion of the banks are building client driven societies with the progression of AI, Natural Language Processing, and subjective figuring. All these are significant for banks to satisfy clients, abstaining from holding up lines in the bank in the coming future.

\section{Data based Artificial Intelligence applications}

A large amount of data can be analyzed effectively with the help of applications installed in personal robots, end-user devices and the financial institution which also helps with projections, predictions and implementing customized financial advice. The financial plans and strategies can be acquired by these applications through research, about loans, rates, tracking the progress and also with customized investment opportunities.

\section{Digital Wallets}

Digital wallets are becoming the future of payment technologies with apps like Apple, Paypal, Google Tez, Paytm and others which are leaping on their on gateways. This reduces the dependency on the physical cash with boosting the reach of money to the higher levels.

\section{Voice Assistance}

Voice Assistance is prompting bit by bit blur off the physical nearness, as innovation is empowering the clients to utilize banking administrations with contact screens and voice directions. Intuitive Voice Response System (IVRS) helps in preparing demands so as to the appropriate response the inquiries, associating clients with different financial administrations and gives the required data. This diminishes blunders which utilized happen on account of the human.

\section{APPLICATION OF AI IN THE COMMERCIAL BANKS STATE BANK OF INDIA}

$\mathrm{SBI}$, which is India's biggest bank with 420 million clients, is leaving on its AI venture from the perspective of the two workers and clients. To fuel its AI mission, this year, SBI propelled a national hackathon, "Code For Bank". SBI is currently using an AI-based solution developed by Chapdex, the winning team from its first hackathon.

\section{HDFC Bank}

HDFC Bank has developed an AI-based chatbot, "Eva”, built by Bengaluru-based Senseforth AI Research. Since its launch in March this year, Eva (which stands Electronic Virtual Assistant) has addressed over 2.7 million customer queries, interacted with over 530,000 unique users, and held 1.2 million conversations.

\section{ICICI BANK}

ICICI Bank, India's second-largest private sector bank has deployed software robotics in over 200 business processes across various functions of the company. ICIC seems to be referring to what is often referred to as "robotic software" a kind of software generally focused on automating office work.

\section{AXIS BANK}

Axis Bank launched an AI \& NLP (Natural Language Processing) enabled app, Conversational Banking, to help consumers with financial and non-financial transactions, answer FAQs and get in touch with the bank for loan other products.

\section{CONCLUSION}

A computerized boom is positively occurring over all fragments of industry particularly banking, particularly after demonetization. The customary banking has advanced and an ever increasing number of banks are embracing new advancements like AI, Cloud, square chain to chop down their working costs what's more, improve proficiency. In spite of the fact that it is still in its early stage,banks are still at cusp of an man-made consciousness transformation. Improvement and advancement in the AI business, will increment efficiency at a decreased expense. Supervisors crosswise over ventures should raise their bet on range of abilities up degree. There is no uncertainty that ongoing push towards digitalization is quickly affecting the customary financial models. Nonetheless, it has likewise presented the organizations to expanding digital security dangers and vulnerabilities. The banks are progressively taking a gander at developing innovations, for example, blockchain and examination in making a functioning safeguard system against cybercrimes.

\section{REFERENCES}

\section{A. BOOKS}

[1] An Introduction to Research Procedure in Social Science - Gopal M.A. - Asia Publishing House Bombay.

[2] Business Research Methodology - Dr K. Ramachandra Himalaya Publication House - Bangalore.

[3] ARTIFICIAL INTELLIGENCE Third Edition - Kevin Knight and Elaine_Rich

[4] Life 3.0: Being Human in the Age of Artificial Intelligence - Max Tegmark 


\section{B. RESEARCH ARTICLES}

[1] Agarwal A, Barniv R, Leach R. 1997. Predicting the outcome following bankruptcy filing: a three-state classification using neural networks. International Journal of Intelligent Systems in Accounting, Finance and Management 6(3): 177-194.

[2] Best PJ, Mohay G, Anderson A. 2004. Machineindependent audit trail analysis - a tool for continuous audit assurance. Intelligent Systems in Accounting, Finance and Management 12(2): 85-102.

[3] Brown CE, Coakley JR. 2000. Artificial neural networks in accounting and finance: modeling issues. International Journal of Intelligent Systems in Accounting, Finance and Management 9: 119-144.

[4] Hansen JV, Messier Jr WF. 1982. Expert systems for decision support in EDP auditing. International Journal of Computer and Information Science (October): $357-$ 379

\section{WEBSITES}

[1] https://www.livemint.com/AI/v0Nd6Xkv0nINDG4wQ 2JOvK/Artificial-Intelligence-in-Indian-bankingChallenges-and-op.html

[2] https://searchenterpriseai.techtarget.com/feature/AIin-banking-industry-brings-operational-improvements

[3] https://www.forbes.com/sites/forbestechcouncil/201 8/12/05/how-artificial-intelligence-is-helpingfinancial-institutions/\#2f01856a460a

[4] http://www.digitaljournal.com/business/indianbanks-turning-to-artificial-intelligence/article/526100

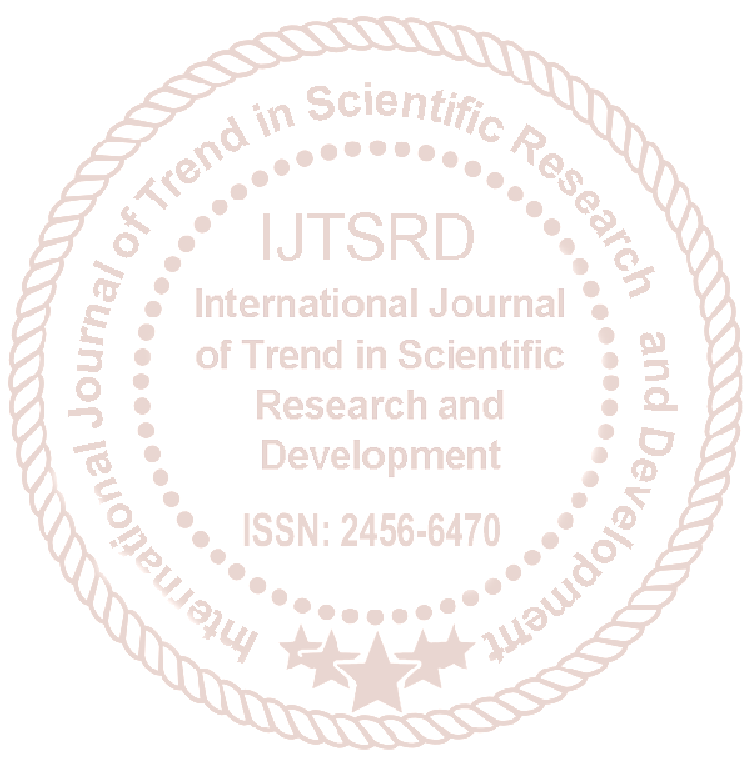

